\title{
miR-455-5p promotes cell invasion and migration in breast cancer
}

\author{
TUERXUNJIANG AILI ${ }^{1}$, XUELAITI PAIZULA $^{2}$ and AISIKEER AYOUFU ${ }^{2}$
}

Departments of ${ }^{1}$ General Medicine and ${ }^{2}$ Mammary Surgery, Affiliated Tumor Hospital

of Xinjiang Medical University, Urumqi, Xinjiang 830011, P.R. China

Received December 11, 2016; Accepted August 7, 2017

DOI: $10.3892 / \mathrm{mmr} .2017 .8101$

\begin{abstract}
MicroRNA (miR)-455-5p has been identified as a biomarker for various types of cancer and may therefore be involved in the regulation of cancer development and progression. However, the specific role and function of miR-455-5p in breast cancer remains unclear. The present study explored the expression levels and function of miR-455-5p in breast cancer. The results from reverse transcription-quantitative polymerase chain reaction analysis revealed that miR-455-5p was significantly upregulated in breast cancer. Clinically, increased expression of miR-455-5p predicted a poor survival rate and miR-455-5p was identified as one of the independent prognostic factors for breast cancer patients. Furthermore, results from wound healing and Transwell assays revealed that miR-455-5p accelerated invasiveness and migration capabilities of breast cancer cells. In addition, programmed cell death 4 was identified as a downstream target of miR-455-5p and its expression was observed to be negatively regulated by miR-455-5p. Overall, miR-455-5p may function as an oncogene in breast cancer, and may therefore be used as a prognostic marker for breast cancer patients.
\end{abstract}

\section{Introduction}

Progression has previously been made regarding the diagnosis and treatment of various cancers associated with mortality in women, however, breast cancer is still considered to be of primary concern worldwide (1). In order to diagnose and treat breast cancer during an earlier progressive stage, the underlying molecular mechanisms of its development and progression need to be elucidated (2).

It has been reported that microRNAs (miRNAs), small RNAs composed of 18-25 nucleotides, are incapable of coding protein, and dysregulated miRNA expression is present in multiple cancers, including breast cancer (3). miRNA is important in cancer progression via an influence on diverse

Correspondence to: $\operatorname{Dr}$ Aisikeer Ayoufu, Department of Mammary Surgery, Affiliated Tumor Hospital of Xinjiang Medical University, 789 Suzhou Road, Urumqi, Xinjiang 830011, P.R. China E-mail: ayoufu@126.com

Key words: MicroRNA-455-5p, breast cancer, migration, invasion cellular activities, including cell growth (4), apoptosis (5), metastasis (6), invasion (7) and the cell cycle (8). MiR-455-5p as an oncogene or tumor suppressor has been verified to be associated with several cancers, including hepatocellular adenoma (9), head and neck squamous cell carcinoma (10) and oral squamous cell carcinoma (11). It has previously been demonstrated that in hepatocellular adenoma tissues and cell lines, miR-455-5p expression levels are deregulated (9). In oral cancer, transforming growth factor (TGF)- $\beta$-mediated highly expressed miR-455-5p promotes cancer progression via decreasing the expression of ubiquitin conjugating enzyme E2 B (UBE2B) (11). Currently, there are not many studies that have been conducted regarding the expression and role of miR-455-5p. The present study demonstrated that miR-455-5p was upregulated in breast cancer. Further statistical analysis revealed that miR-455-5p was notably associated with breast cancer patient prognosis. Cytological experimental results demonstrated that miR-455-5p exerted a positive influence on breast cancer cell migratory and invasive abilities.

Previous studies have reported that miRNAs directly interact with their targets to regulate tumor progression (12). In gastric cancer, miR-455-5p acts as a tumor suppressor via targeting and downregulating RAB18, member RAS oncogene family RAB18 (13). The present study demonstrated that miR-455-5p targeted and negatively regulated programmed cell death (PDCD)4, which has been identified as a tumor suppressor in breast cancer, and inhibits breast cancer cell migration, invasion and growth. Overall, the results of the present study suggest that miR-455-5p acts as a biomarker that may be used in the prediction of breast cancer patient prognosis, in addition to aiding in the development of novel molecular targets and therapeutic strategies to treat the disease.

\section{Patients and methods}

Patients and tissue samples. A total of 70 paired breast cancer tissue samples and adjacent normal tissues were collected from patients (age range, 24-76 years) following confirmation of written informed consent. All the patients underwent surgical resections at the Affiliated Tumor Hospital of Xinjiang Medical University (Urumqi, China), during the period of January 2010-March 2016. The present study gained the approval of the Ethics Committee of the Affiliated Tumor Hospital of Xinjiang Medical University. Prior to mastectomy, the 70 patients had not received radiotherapy or chemotherapy. The extracted specimens were verified as breast cancer tissue with pathological 
diagnosis according to the International Union against Cancer. All fresh samples were immediately placed in a liquid nitrogen container and then stored at $-80^{\circ} \mathrm{C}$ for further analysis.

Reverse transcription-quantitative polymerase chain reaction $(R T$ - $q P C R)$. Invitrogen TRIzol ${ }^{\circledR}$ reagent (Thermo Fisher Scientific, Inc., Waltham, MA, USA) was used to isolate total RNA samples from tissues or cells. In order to obtain cDNA, the All-in-One miRNA qRT-PCR kit (GeneCopoeia,Inc., Rockville, MD, USA) was used for conduction of reverse transcription and the PCR reaction, according to the manufacturer's protocol. For reverse transcription, the reaction was incubated at $42^{\circ} \mathrm{C}$ for $15 \mathrm{~min}$; heated to $95^{\circ} \mathrm{C}$ for $5 \mathrm{~min}$ and finally incubated at $5^{\circ} \mathrm{C}$ for $5 \mathrm{~min}$. Stem-loop primers used for reverse transcription of miR-455-5p and U6 were 5'-GTCGTATCGAGTGGAGCG TCGAGCTATACGCACTCGATACGACACAAA-3' and 5'-GTCCTATCCAGTGCAGGGTCCGAGGTGCACTGGATA CGACAAAATATGGAAC-3', respectively. For RT-qPCR, the following thermocycling conditions were used: Initial denaturation at $95^{\circ} \mathrm{C}$ for $5 \mathrm{~min}$; followed by 40 cycles of denaturation at $95^{\circ} \mathrm{C}$ for $15 \mathrm{sec}$ and annealing/elongation at $60^{\circ} \mathrm{C}$ for $30 \mathrm{sec}$. The PCR primers for U6 and miR-455-5p were obtained from GeneCopoeia, Inc. The PCR primer sequences were as follows: U6 forward, 5'-CGCTTCGGCAGCACATAT ACTA-3' and reverse, 5'-CGCTTCACGAATTTGCGTGTC A-3'; miR-455-5p forward, 5'-CGAGCTTCCTTCTGCAGGT-3' and reverse, 5'-CACCACTGCCATCCCACA-3'. The 2- $2^{-\Delta \mathrm{Cq}}$ method was used to quantify the level of miRNA (14).

Cell culture and transfection. The breast cancer cell lines, including MDA-MB-453, MCF-7, SK-BR-3, MDA-MB-231 and the normal breast cell line MCF-10A were purchased from American Type Culture collection (Manassas, VA, USA), then cultured with Dulbecco's modified Eagle medium (Thermo Fisher Scientific, Inc.) supplemented with $10 \%$ fetal bovine serum (Gibco; Thermo Fisher Scientific, Inc.) and 1\% penicillin-streptomycin (GE Healthcare Life Sciences, Logan, UT, USA). All of the cells were maintained in an incubator at $37^{\circ} \mathrm{C}$, in an environment containing $5 \% \mathrm{CO}_{2}$. The miR-455-5p inhibitors (5'-CGAUGUAGUCCAAAGGCACAUA-3') and negative control (NC) (5'-UUCUCCGAACGUGUCACGUTT-3') were obtained from Shanghai GenePharma Co., Ltd., (Shanghai, China). Cells underwent the transfection procedure when the cell confluence reached $50-70 \%$, using Lipofectamine ${ }^{\circledR} 2000$ (Thermo Fisher Scientific, Inc.) according to the manufacturer's protocol. The final concentrations of the mimics and its corresponding $\mathrm{NC}$ were adjusted to $50 \mathrm{nM}$ (6-well plate), while inhibitors and its NC were modulated to $200 \mathrm{nM}$ (6-well plate). Total RNA and protein was extracted $24 \mathrm{~h}$ following transfection, and the cells were harvested $48 \mathrm{~h}$ following transfection for the subsequent experiments.

Wound-healing assay. The 6-well plates were used to culture cells $\left(5 \times 10^{5}\right)$ and scratch wounds were created using a $200 \mu 1$ pipette tip. Following a culture period of 0 and 48 h, cells were washed three times using sterile PBS to remove cellular debris, then were imaged under an inverted microscope.

Transwell assay. The cell migratory and invasive abilities were detected using non-Matrigel-coated/Matrigel-coated chambers, respectively (BD Biosciences, Franklin Lakes, NJ, CA, USA). Dulbecco's modified Eagle's medium supplemented with $10 \%$ FBS was added into the lower chambers. MDA-MB-231 and MCF-7 cells (1×10 ${ }^{5}$ cells/well), which had been transfected with miR-455-5p inhibitors or NC, were plated into the upper chambers. Following incubation for 24 or $48 \mathrm{~h}$, the cells that remained in the upper chambers were removed by PBS and cotton swabs. Following this, $4 \%$ paraformaldehyde was used to fix cells at room temperature for $30 \mathrm{~min}$, which had passed through the filters, and cells were stained with $0.1 \%$ crystal violet at room temperature for $5 \mathrm{~min}$. Cells were observed and imaged using a fluorescence microscope (Olympus Corporation, Tokyo, Japan; magnification, $\mathrm{x} 100$ ) and 5 separate fields were used for every filter to obtain an average.

Western blotting. Total protein was extracted from breast cancer cells using a radioimmunoprecipitation assay lysis buffer (Beyotime Institute of Biotechnology,Haimen, China), according to the manufacturer's protocol. The protein concentration was determined using the bicinchonininc protein assay kit (Thermo Fisher Scientific, Inc.). Following separation by $10 \%$ SDS-PAGE (25 $\mu \mathrm{g} /$ lane), the proteins were transferred to a polyvinlyidene membrane. Then, the membrane was blocked using 5\% non-fat milk at room temperature for $2 \mathrm{~h}$ and incubated with PDCD4 (Cell Signaling Technology, Inc., Danvers, MA, USA) or $\beta$-actin (Sigma-Aldrich; Merck KGaA, Darmstadt, Germany) primary antibodies, overnight at $4^{\circ} \mathrm{C}$. The primary antibodies included anti-PDCD4 (1:1,000; cat. no. ab51495; Abcam, Cambridge, MA, USA) and anti- $\beta$-actin (1:1,000; cat. no. ab8226; Abcam). Following incubation with their respective secondary antibodies at room temperature for $1 \mathrm{~h}$ the proteins were visualized using an enhanced chemiluminescence chromogenic substrate [Multi Sciences (Lianke) Biotech Co., Ltd., Hangzhou, China]. The secondary antibodies included goat anti-mouse $\operatorname{IgG} 2 \mathrm{~b}(1: 8,000$; cat. no. sc-2062; Santa Cruz Biotechnology, Inc., Dallas, TX, USA) and goat anti-rabbit $\operatorname{IgG} 2 b$ (1:8,000; cat. no. sc-2004; Santa Cruz Biotechnology, Inc.). The immune complexes were quantified using Image $\mathbf{J}$ (version 1.46; National Institutes of Health, Bethesda, MA, USA).

Bioinformatics analysis. Bioinformatics tools TargetScan (www.targetscan.org), miRNA.org (www.microrna.org) and miRbase (www.mirdb.org) were used to predict the targets of miR-455-5p. Then the data from the three databases were combined to obtain the most popular candidates in the three databases using Microsoft Excel (version 2017; Microsoft Corporation, Redmond, Washington) and SPSS software (version 22.0; IBM SPSS, Armonk, NY, USA).

Statistical analysis. Data was analyzed using the Kaplan-Meier method, unpaired Student's t-test, $\chi^{2}$ test, analysis of variance followed by the least significant difference test and univariate and multivariate Cox regression analysis. SPSS software, version 22.0 (IBM SPSS, Armonk, NY, USA) was used to analyze data. All the presented data were expressed as the mean \pm standard deviation. Images were created using GraphPad Prism software (version 6; GraphPad Software, Inc., La Jolla, CA, USA). $\mathrm{P}<0.05$ was considered to indicate a statistically significant difference. 
Table I. Association between miR-455-5p expression level and clinical characteristics.

\begin{tabular}{|c|c|c|c|c|}
\hline \multirow[b]{2}{*}{ Clinical characteristics } & \multirow{2}{*}{$\begin{array}{c}\text { Cases } \\
(n=70)\end{array}$} & \multicolumn{2}{|c|}{ miR455-5p expression } & \multirow[b]{2}{*}{ P-value } \\
\hline & & High $(n=36)$ & Low $(n=34)$ & \\
\hline \multicolumn{5}{|l|}{ Age, years } \\
\hline$<45$ & 29 & 13 & 16 & \multirow[t]{2}{*}{0.467} \\
\hline$\geq 45$ & 41 & 23 & 18 & \\
\hline \multicolumn{5}{|l|}{ Tumor size, $\mathrm{cm}$} \\
\hline$<2$ & 23 & 13 & 10 & \multirow[t]{2}{*}{0.616} \\
\hline$\geq 2$ & 47 & 23 & 24 & \\
\hline \multicolumn{5}{|l|}{ Tumor location } \\
\hline Left & 34 & 16 & 18 & \multirow[t]{2}{*}{0.633} \\
\hline Right & 36 & 20 & 16 & \\
\hline \multicolumn{5}{|l|}{ Differentiation } \\
\hline Moderate/High & 26 & 7 & 19 & \multirow[t]{2}{*}{$0.003^{b}$} \\
\hline Low & 44 & 29 & 15 & \\
\hline \multicolumn{5}{|l|}{ Lymph node metastasis } \\
\hline Negative & 15 & 12 & 3 & \multirow[t]{2}{*}{$0.019^{\mathrm{a}}$} \\
\hline Positive & 55 & 24 & 31 & \\
\hline \multicolumn{5}{|l|}{ TNM stage } \\
\hline $\mathrm{I} / \mathrm{II}$ & 38 & 31 & 17 & \multirow[t]{2}{*}{$0.002^{\mathrm{b}}$} \\
\hline III/IV & 32 & 5 & 17 & \\
\hline \multicolumn{5}{|l|}{ ER status } \\
\hline Negative & 37 & 16 & 22 & \multirow[t]{2}{*}{0.100} \\
\hline Positive & 33 & 20 & 12 & \\
\hline \multicolumn{5}{|l|}{ HER2 status } \\
\hline Negative & 28 & 17 & 20 & \multirow[t]{2}{*}{0.350} \\
\hline Positive & 42 & 19 & 14 & \\
\hline \multicolumn{5}{|l|}{ PR status } \\
\hline Negative & & 16 & 12 & \multirow[t]{2}{*}{0.473} \\
\hline Positive & & 20 & 22 & \\
\hline
\end{tabular}

${ }^{\mathrm{a}} \mathrm{P}<0.05,{ }^{\mathrm{b}} \mathrm{P}<0.01$; TNM, tumor node metastasis; ER, estrogen receptor; HER2, human epidermal growth factor receptor 2; PR, progesterone receptor.

\section{Results}

Expression of miR-455-5p in breast cancer tissues increases. The present study explored miR-455-5p expression levels in 70 paired breast cancer and adjacent non-cancerous tissue samples. Results from RT-qPCR revealed that compared with control group, miR-455-5p expression levels in breast cancer tissues were notably increased (Fig. 1; P<0.01). Therefore, miR-455-5p may be considered a valuable oncogene in the progression of breast cancer.

Clinical significance of miR-455-5p expression in breast cancer. Based on miR-455-5p average expression level (7.02; range, 6.87-7.11), the 70 breast cancer patients were categorized into two groups, low miR-455-5p and high miR-455-5p groups. Then, the correlations between clinical characteristics and miR-455-5p expression were assessed. The analysis revealed that $\mathrm{miR}-455-5 \mathrm{p}$ expression was notably

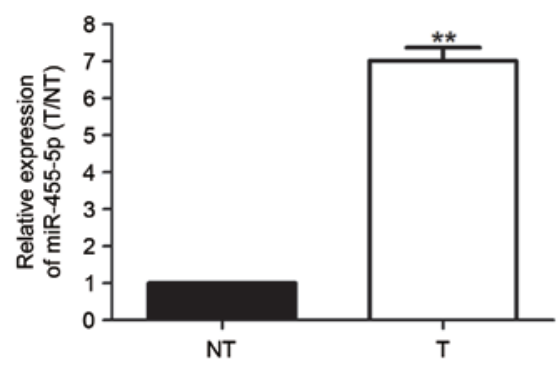

Figure 1. Expression of miR-455-5p in breast cancer tissues. Reverse transcription-quantitative polymerase chain reaction results revealed that the mean expression of miR-455-5p in cancerous tissues was significantly increased compared with control group. ${ }^{* *} \mathrm{P}<0.01$ vs. NT. miR, microRNA; T; tumor tissues; NT, non-tumor tissues.

correlated with TNM stage, lymph node metastasis and tumor differentiation $(\mathrm{P}<0.05$; Table I). Additionally, univariate Cox regression analysis (Table II) and multivariate Cox regression 
Table II. Univariate Cox regression analysis for the identification of prognostic factors for overall survival and disease-free survival time in patients with breast cancer.

Overall survival

\begin{tabular}{|c|c|c|c|c|}
\hline \multirow[b]{2}{*}{ Variables } & & \\
\hline & $\mathrm{HR}(95 \% \mathrm{CI})$ & P-value & $\mathrm{HR}(95 \% \mathrm{CI})$ & P-value \\
\hline Age, years $(<45$ vs. $\geq 45)$ & $1.853(1.251-2.104)$ & 0.568 & $1.532(1.463-1.604)$ & 0.845 \\
\hline Tumor size, $\mathrm{cm}(<2$ vs. $\geq 2)$ & $1.332(1.238-1.457)$ & 0.697 & $1.792(1.659-1.846)$ & 0.446 \\
\hline Tumor location (left vs. right) & $1.643(1.549-1.784)$ & 0.297 & $1.406(1.379-1.523)$ & 0.684 \\
\hline $\begin{array}{l}\text { Differentiation } \\
\text { (moderate/high vs. low) }\end{array}$ & $2.729(2.654-2.803)$ & 0.042 & $2.912(2.878-3.041)$ & 0.004 \\
\hline $\begin{array}{l}\text { Lymph node metastasis } \\
\text { (negative vs. positive) }\end{array}$ & $1.478(1.238-1.739)$ & 0.007 & $1.649(1.587-1.882)$ & 0.015 \\
\hline TNM stage (I/II vs. III/IV) & $1.193(1.046-1.254)$ & 0.026 & $1.264(1.206-1.321)$ & 0.043 \\
\hline $\begin{array}{l}\text { ER status } \\
\text { (negative vs. positive) }\end{array}$ & $1.774(1.536-1.862)$ & 0.922 & $2.012(1.897-2.145)$ & 0.238 \\
\hline $\begin{array}{l}\text { HER2 status } \\
\text { (negative vs. positive) }\end{array}$ & $1.547(1.502-1.621)$ & 0.218 & $1.708(1.654-1.783)$ & 0.465 \\
\hline $\begin{array}{l}\text { PR status } \\
\text { (negative vs. positive) }\end{array}$ & $2.745(2.133-3.027)$ & 0.589 & $1.965(1.457-2.541)$ & 0.628 \\
\hline $\begin{array}{l}\text { miR- } 455-5 p \text { relative expression } \\
(<7.02 \text { vs. } \geq 7.02)\end{array}$ & $2.612(2.544-2.764)$ & 0.024 & $2.832(2.478-3.007)$ & 0.017 \\
\hline
\end{tabular}

HR, hazard ratio; CI, confidence interval; OS, overall survival; HER2, human epidermal growth factor receptor 2; ER, estrogen receptor; PR, progesterone receptor; TNM, tumor node metastasis. $\mathrm{n}=70$.

A

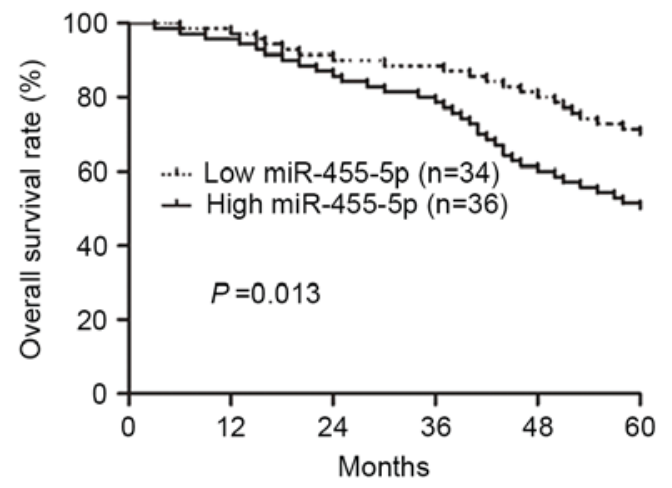

B

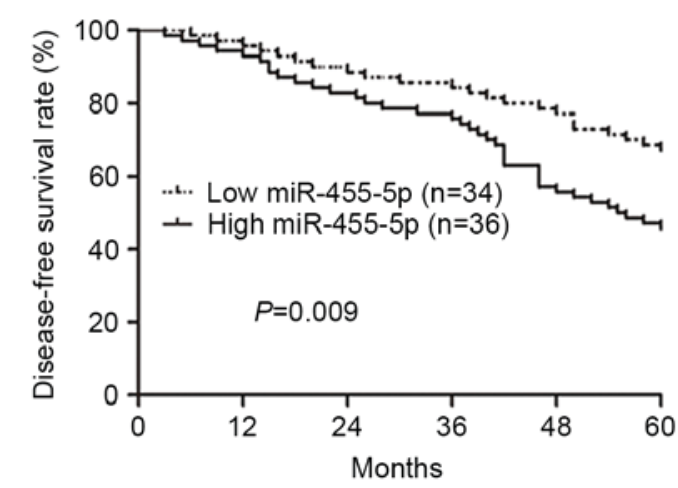

Figure 2. Effects of miR-455-5p expression on breast cancer patient prognosis. Patients in the high miR-455-5p expression group exhibited a significantly poorer (A) overall survival rate and $(\mathrm{B})$ disease-free survival rate. $\mathrm{P}<0.05$. miR, microRNA.

analysis (Table III) were conducted for the identification of prognostic factors for overall survival (OS) and disease-free survival (DFS) time in patients with breast cancer. Results revealed that TNM stage, lymph node metastasis, tumor differentiation and miR-255-5p were prognostic factors of patients with breast cancer. Therefore, it was hypothesized that miR-455-5p may be associated with the survival rate of breast cancer and may be used to predict the prognosis of breast cancer patients.

Elevated miR-455-5p is associated with poor prognosis of breast cancer. The present study compared the survival rate of two groups of patients using Kaplan-Meier survival analysis, and it was revealed that patients with increased expression of miR-455-5p exhibited a poorer OS and DFS rate compared with lower miR-455-5p expression $(\mathrm{P}=0.013, \mathrm{P}=0.009$, respectively; Fig. 2A and $\mathrm{B}$ ). Furthermore, univariate and multivariate Cox proportional hazard regression analysis were conducted to explore whether miR-455-5p acts as an independent prognostic factor in breast cancer. The data demonstrated that miR-455-5p expression, TNM stage and lymph node metastasis were independent prognostic factors of breast cancer patients, which may be used to predict their prognosis $(\mathrm{P}<0.05$; Table II). The results demonstrated that miR-455-5p may act as an independent prognostic factor for breast cancer patients. 
Table III. Multivariate Cox regression analysis for the identification of prognostic factors for overall survival and disease-free survival time in patients with breast cancer.

\begin{tabular}{llcc}
\hline & \multicolumn{1}{c}{ Overall survival } & & Disease-free survival \\
\cline { 2 - 3 } Variables & HR $(95 \% \mathrm{CI})$ & P-value & HR (95\% CI) \\
\hline $\begin{array}{l}\text { Differentiation } \\
\text { (moderate/high vs. low) }\end{array}$ & $1.894(1.761-2.327)$ & 0.918 & $1.664(1.498-1.863)$ \\
$\begin{array}{l}\text { Lymph node metastasis } \\
\text { (negative vs. positive) }\end{array}$ & $2.003(1.847-2.214)$ & 0.028 & $2.784(2.516-2.943)$ \\
$\begin{array}{l}\text { TNM stage } \\
(\text { negative vs. positive) } \\
\text { miR-455-5p relative expression } \\
(<7.02 \text { vs. } \geq 7.02)\end{array}$ & $1.339(1.235-1.456)$ & 0.026 & $1.649(1.468-1.892)$ \\
\hline
\end{tabular}

HR, hazard ratio; CI, confidence interval; OS, overall survival; TNM, tumor node metastasis. $\mathrm{n}=70$.

A

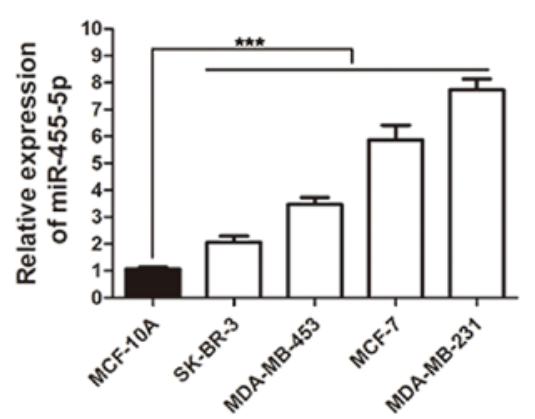

B miR-455-5p NC
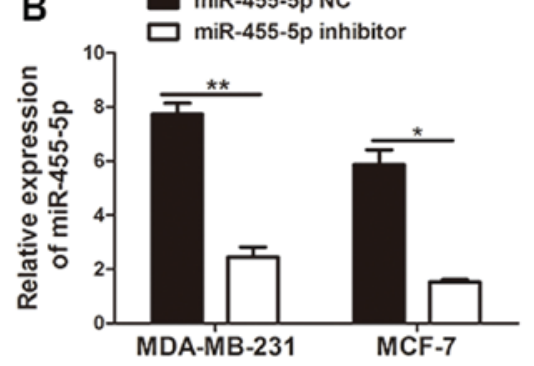

Figure 3. Expression of miR-455-5p in breast cancer cell lines. Reverse transcription-quantitative polymerase chain reaction data revealed that (A) mean expression levels of miR-455-5p in cancer cell lines were significantly increased compared with normal cell MCF-10A. (B) Expression levels of miR-455-5p in MDA-MB-231 and MCF-7 cells that were transfected with miR-455-5p inhibitor and negative control were measured. ${ }^{*} \mathrm{P}<0.05,{ }^{* *} \mathrm{P}<0.01,{ }^{* * *} \mathrm{P}<0.001$. miR, microRNA; NC, negative analysis.

MiR-455-5p is overexpressed in breast cancer cell lines. RT-qPCR was used to measure the expression of miR-455-5p in breast cancer cell lines, including MDA-MB-453, MCF-7, SK-BR-3 and MDA-MB-231, in addition to the normal cell line MCF-10A. Consistent with the clinical results, the experiment revealed that when compared with MCF-10A cells, miR-455-5p expression in all breast cancer cell lines was markedly upregulated ( $\mathrm{P}<0.001$; Fig. 3A). MDA-MB-231 and MCF-7 cells exhibited a relatively increased expression of miR-455-5p, and the two cell types were therefore selected to be used in further experiments. To explore the function of miR-455-5p in breast cancer progression, the miR-455-5p expression in MCF-7 cells and MDA-MB-231 cells was manipulated via transfection with miR-455-5p inhibitor or NC into cells. The results of the RT-qPCR demonstrated that the miR-455-5p inhibitor markedly repressed miR-455-5p expression in these cell lines (Fig. 3B; $\mathrm{P}<0.05$ ).

MiR-455-5p promotes cell invasion and migration. Furthermore, the present study investigated whether miR-711 promotes invasion and migration abilities of breast cancer cells, using wound healing and Transwell assays. The results indicated that compared with the NC, the groups with downregulated miR-455-5p via miR-455-5p inhibitor transfection, exhibited suppressed invasion and migration abilities (Figs. 4 and 5; $\mathrm{P}<0.05$ ). Therefore, the findings demonstrated that miR-455-5p facilitated breast cancer cell migratory and invasive abilities.

PDCD4 is a downstream target of miR-455-5p in breast cancer cells. In order to uncover the functional mechanism of miR-455-5p in breast cancer, the present study explored the potential targets of miR-455-5p using bioinformatic tools (TargetScan, miRNA.org and miRbase). The results suggested that PDCD4 acted as a downstream target of miR-455-5p (Fig. 6A). Following this, the expression levels of PDCD4 were detected by western blotting in MCF-7 and MDA-MB-231 cells, which had been transfected with the miR-455-5p inhibitor. The results demonstrated that the expression of PDCD4 was significantly increased in these two breast cancer cell lines transfected with the miR-455-5p inhibitor, compared with the NC group $(\mathrm{P}<0.05$; Fig. $6 \mathrm{~B}$ and $\mathrm{C})$. Therefore, PDCD 4 may be negatively regulated by miR-455-5p in breast cancer cells. Overall, the findings demonstrated that PDCD4 may act as a downstream target of miR-455-5p in breast cancer cells. 
A
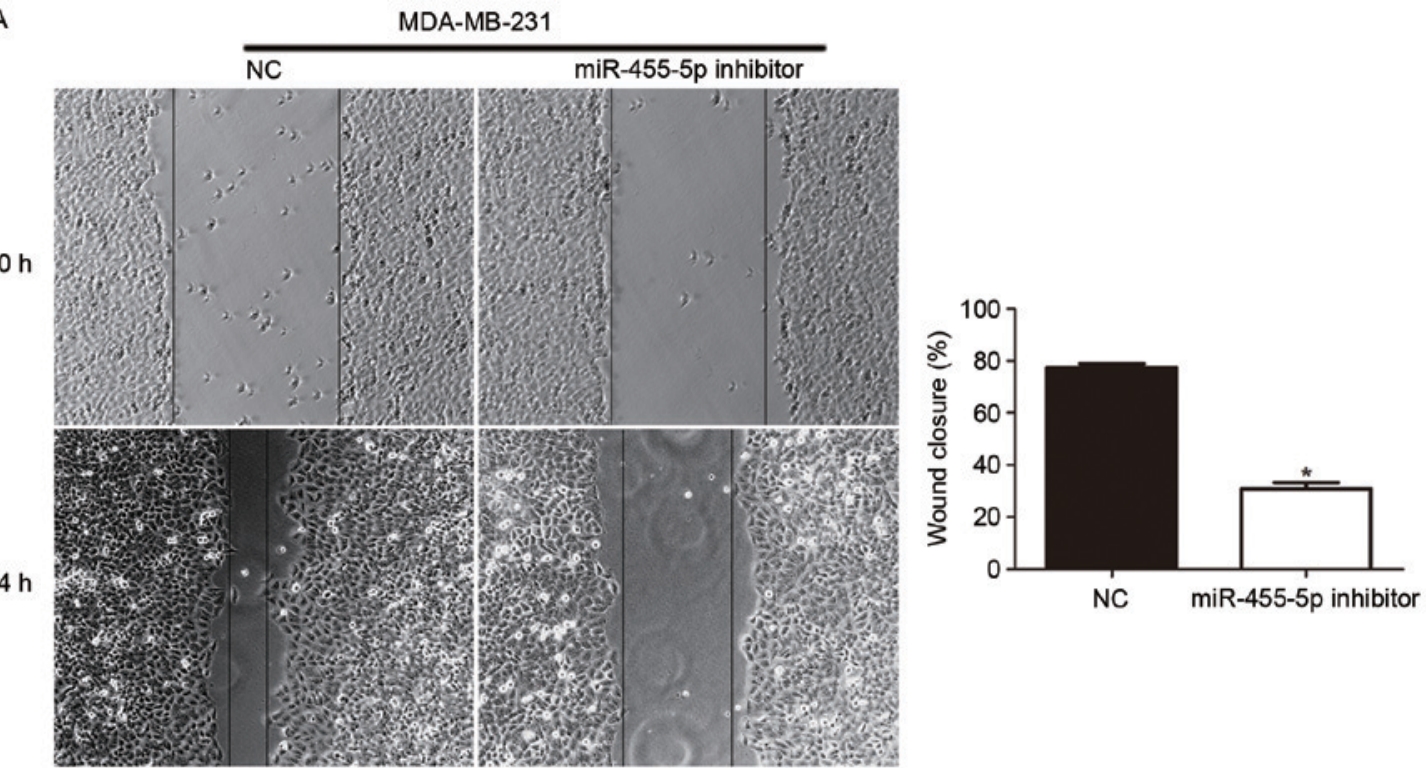

B

MCF-7

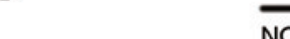

NC

miR-455-5p inhibitor
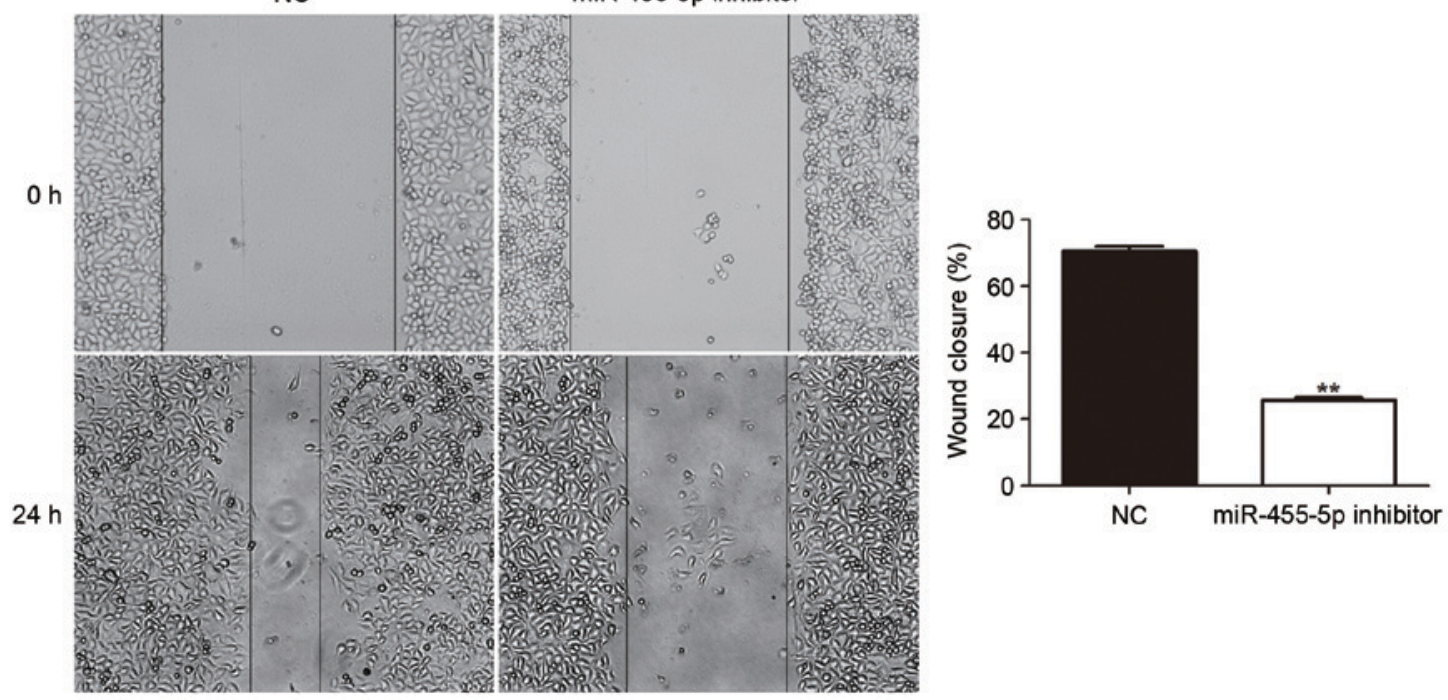

Figure 4. MiR-455-5p promotes breast cancer cell mobility. Downregulated miR-455-5p suppressed cell mobility as measured by wound healing assay in (A) MDA-MB-231 cells and (B) MCF-7 cells. ${ }^{*} \mathrm{P}<0.05,{ }^{* *} \mathrm{P}<0.01$ vs. NC. miR, microRNA; NC, negative control.

\section{Discussion}

The diagnosis and treatment strategies regarding breast cancer have markedly improved over previous years, however patients currently still exhibit a poor prognosis (15). There are $>1$ million newly diagnosed cases of male breast cancer each year, and breast cancer results in $\sim 520,000$ mortalities each year worldwide (16). Therefore, development of novel treatment strategies for breast cancer is of primary concern.

miRNAs have been extensively investigated as effective prognostic biomarkers for cancer, including breast cancer $(17,18)$. It has previously been reported that miR-145 exhibits a suppressive role in the regulation of breast cancer cell migration through specifically inhibiting the expression of fascin and epithelial to mesenchymal transition progression (19). Zhang et al (20) demonstrated that low expression of miR-124-3p promotes breast cancer cell development, primarily by increasing beclin-1 expression. Wu et al (21) suggested that in breast cancer, miR-613 negatively regulates vascular endothelial growth factor expression and restrains the cell proliferation and invasion. Notably, miR-455-5p has been identified as an oncogene or anti-oncogene in previous studies $(11,13,22)$. In gastric cancer, miR-455-5p has been identified as a tumor suppressor, which decreases the expression of RAB18 (13). Conversely, TGF- $\beta$-induced miR-455-5p is overexpressed, which results in low expression of UBE2B and promotes cancer progression (11). In the present study, the data indicated that in breast cancer tissues and cell lines, miR-455-5p expression levels were significantly upregulated, which suggested that miR-455-5p may act as an oncogene in breast cancer.

Malignant tumors with poor tumor differentiation tend to present more lymph node metastasis and an advanced TNM stage, which results in an increased tendency of tumor metastasis and invasion $(23,24)$. The present study demonstrated that miR-455-5p was closely correlated with lymph node metastasis, TNM stage and tumor differentiation. 

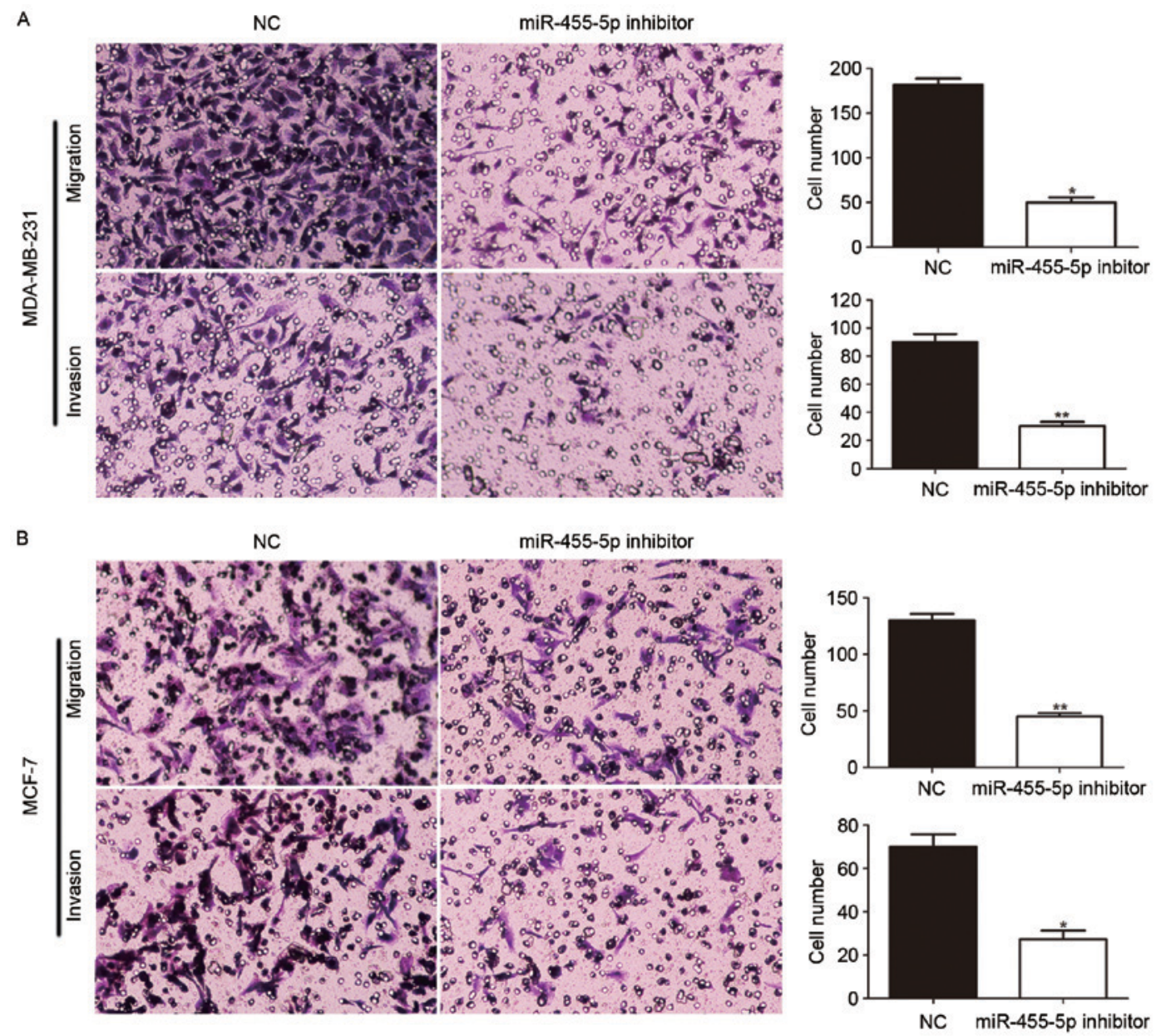

Figure 5. MiR-455-5p promotes breast cancer cell migration and invasion. Downregulated miR-455-5p suppressed cell mobility as measured by Transwell assays in (A) MDA-MB-231 and (B) MCF-7 cells. ${ }^{*} \mathrm{P}<0.05,{ }^{* * *} \mathrm{P}<0.01$ vs. NC. miR, microRNA; NC, negative control.

A

miR-455-5p 3'-gcuacauCAGGUUUCCGUGUAu-5'

PDCD4 5'-auuaaacGUGACAUGGCACAUa-3'

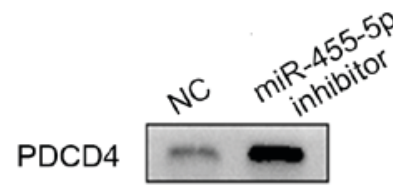

$\beta$-actin

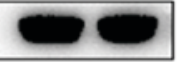

MDA-MB-231

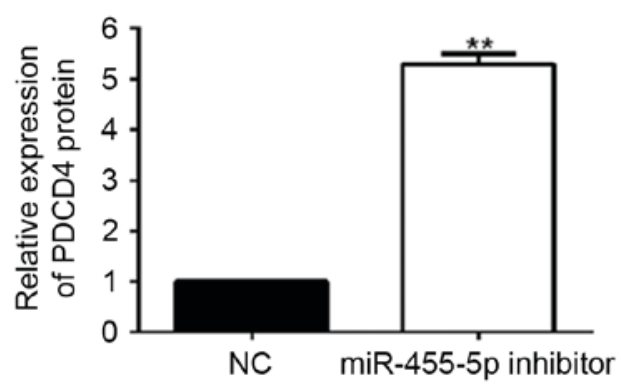

C

PDCD4

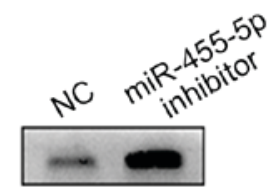

$\beta$-actin

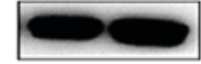

MCF-7

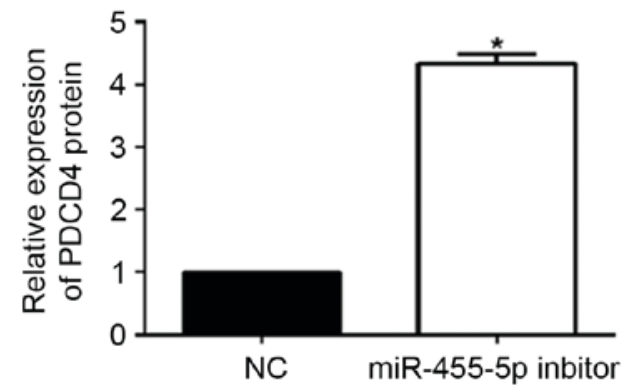

Figure 6. PDCD4 is a downstream target of miR-455-5p. (A) Bioinformatic analysis suggested that miR-455-5p directly targeted the 3'-untranslated region of PDCD4. (B) Western blotting demonstrated that the expression of PDCD4 was significantly increased in (B) MDA-MB-231 and (C) MCF-7 cells transfected with the miR-455-5p inhibitor. ${ }^{*} \mathrm{P}<0.05,{ }^{* *} \mathrm{P}<0.01$ vs. NC. miR, microRNA; NC, negative control; PDCD4, programmed cell death 4. 
Further analysis indicated that upregulated miR-455-5p was additionally associated with poorer OS and DFS survival rates. The results additionally revealed that TNM stage, lymph node metastasis, tumor differentiation and miR-255-5p acted as prognostic factors for patients with breast cancer. It was therefore hypothesized that miR-455-5p acts as an oncogene to promote migration and invasion of breast cancer.

Next, cytological experiments indicated that silencing miR-455-5p had a suppressive effect in terms of the invasive and migratory abilities of breast cancer cells. This indicated that miR-455-5p may promote breast cancer progression by accelerating cell migration and invasion.

MiRNAs exert various functions in cancer cells via interaction with specific targets $(11,12)$. In oral squamous cell carcinoma, UBE2B has been identified as a target of miR-455-5p (11). In gastric cancer, miR-455-5p may directly target RAB18 (13). Therefore, in order to identify a target of miR-455-5p in breast cancer, the present study applied bioinformatics tools to analyze potential targets. PDCD4 was subsequently identified as a potential target, and has previously been verified to act as a tumor suppressor in multiple cancers, including breast cancer (25-27). PDCD4 is regulated by various miRNAs in breast cancer, including miR-183-5p and miR-21 $(28,29)$. In order to verify PDCD4 as a target of miR-455-5p, the protein expression of PDCD4 was detected in breast cancer cells, where the expression of miR-455-5p had been decreased. It was revealed that miR-455-5p inversely regulated PDCD4 expression levels in breast cancer cells.

In conclusion, the results of the present study identified PDCD4 as a downstream target of miR-455-5p. However, further studies are required in order to validate this finding, and explore the underlying molecular mechanism of the role of miR-455-5p in breast cancer. The findings demonstrated that miR-455-5p was highly expressed in breast cancer, and therefore may facilitate cancer development, acting as an oncogene and biomarker for the prognosis of breast cancer patients.

\section{References}

1. Torre LA, Bray F, Siegel RL, Ferlay J, Lortet-Tieulent J and Jemal A: Global cancer statistics, 2012. CA Cancer J Clin 65: 87-108, 2015.

2. Rangarajan B, Shet T, Wadasadawala T, Nair NS, Sairam RM, Hingmire SS and Bajpai J: Breast cancer: An overview of published Indian data. South Asian J Cancer 5: 86-92, 2016.

3. Onyido EK, Sweeney E and Nateri AS: Wnt-signalling pathways and microRNAs network in carcinogenesis: Experimental and bioinformatics approaches. Mol Cancer 15: 56, 2016.

4. Cheng W, Yan K, Xie LY, Chen F, Yu HC, Huang YX and Dang CX: MiR-143-3p controls TGF- $\beta 1$-induced cell proliferation and extracellular matrix production in airway smooth muscle via negative regulation of the nuclear factor of activated $T$ cells 1 . Mol Immunol 78: 133-139, 2016.

5. Sun X, Li Y, Zheng M, Zuo W and Zheng W: MicroRNA-223 increases the sensitivity of triple-negative breast cancer stem cells to TRAIL-induced apoptosis by targeting HAX-1. PLoS One 11: e0162754, 2016.

6. Ma L: MicroRNA and metastasis. Adv Cancer Res 132: 165-207, 2016.

7. Zhang Z, Zhang M, Chen Q and Zhang Q: Downregulation of microRNA-145 promotes epithelial-mesenchymal transition via regulating Snail in osteosarcoma. Cancer Gene Ther 24: 83-88, 2017.

8. Del Rosario RC, Damasco JR and Aguda BD: MicroRNA inhibition fine-tunes and provides robustness to the restriction point switch of the cell cycle. Sci Rep 6: 32823, 2016.
9. Chiu LY, Kishnani PS, Chuang TP, Tang CY, Liu CY, Bali D, Koeberl D, Austin S, Boyette K, Weinstein DA, et al: Identification of differentially expressed microRNAs in human hepatocellular adenoma associated with type I glycogen storage disease: A potential utility as biomarkers. J Gastroenterol 49: 1274-1284, 2014.

10. Wong N, Khwaja SS, Baker CM, Gay HA, Thorstad WL, Daly MD, Lewis JS Jr and Wang X: Prognostic microRNA signatures derived from The cancer genome atlas for head and neck squamous cell carcinomas. Cancer Med 5: 1619-1628, 2016.

11. Cheng CM, Shiah SG, Huang CC, Hsiao JR and Chang JY: Up-regulation of miR-455-5p by the TGF- $\beta$-SMAD signalling axis promotes the proliferation of oral squamous cancer cells by targeting UBE2B. J Pathol 240: 38-49, 2016.

12. Dong Y, He D, Peng Z, Peng W, Shi W, Wang J, Li B, Zhang C and Duan C: Circular RNAs in cancer: An emerging key player. J Hematol Oncol 10: 2, 2017.

13. Liu J, Zhang J, Li Y, Wang L, Sui B and Dai D: MiR-455-5p acts as a novel tumor suppressor in gastric cancer by down-regulating RAB18. Gene 592: 308-315, 2016.

14. Livak KJ and Schmittgen TD: Analysis of relative gene expression data using real-time quantitative PCR and the 2(-Delta Delta C(T)) method. Methods 25: 402-408, 2001.

15. Lei L, Wang X and Chen Z: PET/CT imaging for monitoring recurrence and evaluating response to treatment in breast cancer. Adv Clin Exp Med 25: 377-382, 2016.

16. Jemal A, Bray F, Center MM, Ferlay J, Ward E and Forman D: Global cancer statistics. CA Cancer J Clin 61: 69-90, 2011.

17. Huan L, Liang LH and He XH: Role of microRNAs in inflammation-associated liver cancer. Cancer Biol Med 13: 407-425, 2016.

18. Nagini S: Breast cancer: Current molecular therapeutic targets and new players. Anticancer Agents Med Chem 17: 152-163, 2017.

19. Zhao H, Kang X, Xia X, Wo L, Gu X, Hu Y, Xie X, Chang H, Lou L and Shen X: miR-145 suppresses breast cancer cell migration by targeting FSCN-1 and inhibiting epithelial-mesenchymal transition. Am J Transl Res 8: 3106-3114, 2016.

20. Zhang F, Wang B, Long H, Yu J, Li F, Hou H and Yang Q: Decreased miR-124-3p expression prompted breast cancer cell progression mainly by targeting beclin-1. Clin Lab 62: 1139-1145, 2016.

21. Wu J, Yuan P, Mao Q, Lu P, Xie T, Yang H and Wang C: miR-613 inhibits proliferation and invasion of breast cancer cell via VEGFA. Biochem Biophys Res Commun 478: 274-278, 2016.

22. Shoshan E, Mobley AK, Braeuer RR, Kamiya T, Huang L, Vasquez ME, Salameh A, Lee HJ, Kim SJ, Ivan C, et al: Reduced adenosine-to-inosine miR-455-5p editing promotes melanoma growth and metastasis. Nat Cell Biol 17: 311-321, 2015.

23. Zhang DH, Yang ZL, Zhou EX, Miao XY, Zou Q, Li JH, Liang LF, Zeng GX and Chen SL: Overexpression of Thy1 and ITGA6 is associated with invasion, metastasis and poor prognosis in human gallbladder carcinoma. Oncol Lett 12: 5136-5144, 2016.

24. Zhang XF, Liu T, Li Y and Li S: Overexpression of long non-coding RNA CCAT1 is a novel biomarker of poor prognosis in patients with breast cancer. Int J Clin Exp Pathol 8: 9440-9445, 2015.

25. Li C, Deng L, Zhi Q, Meng Q, Qian A, Sang H, Li X and Xia J: MicroRNA-183 functions as an oncogene by regulating PDCD4 in gastric cancer. Anticancer Agents Med Chem 16: 447-455, 2016.

26. Li JZ, Gao W, Lei WB, Zhao J, Chan JY, Wei WI, Ho WK and Wong TS: MicroRNA 744-3p promotes MMP-9-mediated metastasis by simultaneously suppressing PDCD4 and PTEN in laryngeal squamous cell carcinoma. Oncotarget 7: 58218-58233, 2016.

27. Li Y, Jiang D, Zhang Q, Liu X and Cai Z: Ubiquitin-specific protease 4 inhibits breast cancer cell growth through the upregulation of PDCD4. Int J Mol Med 38: 803-811, 2016.

28. Cheng Y, Xiang G, Meng Y and Dong R: MiRNA-183-5p promotes cell proliferation and inhibits apoptosis in human breast cancer by targeting the PDCD4. Reprod Biol 16: 225-233, 2016.

29. Venturutti L, Romero LV, Urtreger AJ, Chervo MF, Cordo Russo RI, Mercogliano MF, Inurrigarro G, Pereyra MG, Proietti CJ, Izzo F, et al: Stat3 regulates ErbB-2 expression and co-opts ErbB-2 nuclear function to induce miR-21 expression, PDCD4 downregulation and breast cancer metastasis. Oncogene 35: 2208-2222, 2016. 